\section{Dual stimuli-responsive multicompartment micelles from triblock terpolymers with tunable hydrophilicity $\dagger$}

\author{
Eva Betthausen, ${ }^{a}$ Markus Drechsler, ${ }^{a}$ Melanie Förtsch, ${ }^{a}$ Felix H. Schacher ${ }^{* b}$ and Axel H. E. Müller ${ }^{* a}$ \\ Received 5th May 2011, Accepted 7th July 2011 \\ DOI: 10.1039/c1sm05822c
}

\begin{abstract}
A plethora of stimuli-responsive micellar aggregates with a compartmentalized shell can be formed in aqueous solution from $\mathrm{ABC}$ triblock terpolymers with tunable hydrophilicity. Polybutadiene-blockpoly(tert-butyl methacrylate)-block-poly(2-(dimethylamino)ethyl methacrylate) (PB-b-P $t$ BMA- $b$ PDMAEMA) and, after modifications by hydrolysis to poly(methacrylic acid) (PMAA) or quaternization to PDMAEMAq, PB-b-PMAA- $b$-PDMAEMAq terpolymers self-assemble in water, depending on $\mathrm{pH}$ and temperature. We demonstrate control over micellar shape, size, and charge via three different preparation pathways. Even more, the micelles are capable of undergoing rearrangements in both the shell and the corona in response to external stimuli like $\mathrm{pH}$ or salinity. In that way, different structures such as multicompartment, core-shell-corona or flower-like micelles were identified and characterized via cryogenic transmission electron microscopy (cryo-TEM) and dynamic light scattering (DLS). The presence of two oppositely charged polyelectrolyte blocks within the structures leads to the formation of intramicellar interpolyelectrolyte complexes (im-IPECs) in the shell of the particles. Surprisingly, the im-IPEC formed between PMAA and PDMAEMAq can be redissolved by changes in $\mathrm{pH}$, even in the absence of additional salt.
\end{abstract}

\section{Introduction}

The design and manipulation of complex nanostructured materials is one of the key issues in current materials science. In particular, the compartmentalization of polymer-based nanostructures has attracted significant attention in the past decades. The inspiration for this concept is drawn from nature, where compartmentalization plays a vital role, as it enables multiple reactions and transport processes in the biological cell to be executed in parallel. The idea to mimic organized biological systems by the preparation of multicompartment nanostructures from block copolymers was introduced by Ringsdorf around 15 years ago. ${ }^{1,2}$ Progress within this field is highlighted in a very recent review. ${ }^{3}$ Such structures are of great interest, as the segregated compartments can combine different properties or

${ }^{a}$ Makromolekulare Chemie II and Bayreuther Zentrum für Kolloide und Grenzfächen, Universität Bayreuth, D-95440 Bayreuth, Germany. E-mail:axel.mueller@uni-bayreuth.de

${ }^{b}$ Institut für Organische Chemie und Makromolekulare Chemie and Jena Center for Soft Matter (JCSM), Friedrich-Schiller-Universität Jena, D07743 Jena, Germany. E-mail: felix.schacher@uni-jena.de

$\dagger$ Electronic supplementary information (ESI) available: FT-IR spectra of $\mathrm{B}_{800} \mathrm{~T}_{200} \mathrm{D}_{285}$ and the terpolymers after modification, $\mathrm{B}_{800} \mathrm{MAA}_{200} \mathrm{D}_{285}$ and $\mathrm{B}_{800} \mathrm{MAA}_{200} \mathrm{Dq}_{285}$ (Fig. S1 and S4); ${ }^{1} \mathrm{H}-\mathrm{NMR}$ spectra of $\mathrm{B}_{800} \mathrm{~T}_{200} \mathrm{D}_{85}$ and $\mathrm{B}_{800} \mathrm{MAA}_{200} \mathrm{D}_{85}$ (Fig. $\mathrm{S} 2$ and $\mathrm{S} 3$ ); additional solution characteristics of $\mathrm{B}_{800} \mathrm{MAA}_{200} \mathrm{Dq}_{285}$ micelles obtained by DLS: $T$ versus $q^{2}$ and $R_{\mathrm{h}}$ versus $c$ at $\theta=90^{\circ}$ (Fig. S5). See DOI: $10.1039 / \mathrm{c} 1 \mathrm{sm} 05822 \mathrm{c}$ chemical functionalities in close proximity. ${ }^{4,5}$ Further, multicompartment micelles are promising candidates for advanced drug-delivery applications, as the different subdomains may solubilize ${ }^{6-8}$ and/or transport payloads of different polarity simultaneously, preventing any undesired interactions before reaching the target site.

The most common approaches towards such structure-withinstructure systems are self-assembly processes of ABC triblock terpolymers in solution. ${ }^{9}$ Bottom-up strategies in, e.g., selective solvents resulted in structures with spherical ${ }^{10-12}$ or cylindrical geometries. ${ }^{13,14}$ Particles exhibiting a compartmentalized core,${ }^{10,11,15,16}$ shell, ${ }^{17,18}$ or corona, ${ }^{19,20}$ as well as Janus micelles ${ }^{20,21}$ have been reported so far.

To date, often terpolymers with two hydrophobic blocks, prevalently hydrocarbon and fluorocarbon segments, are used due to the strong incompatibility between them. This strategy has been pursued with both linear ${ }^{10,20,22}$ and miktoarm star architectures. ${ }^{14,15,23}$ Apart from this, the concept of utilizing two solvophobic blocks with a high mutual incompatibility has also been shown for non-fluorinated terpolymers. ${ }^{11,24-26}$ The use of organic amines as additives for terpolymers containing a poly (acrylic acid) (PAA) block in combination with particular solvent mixtures as a trigger for compartmentalization was demonstrated by Wooley and Pochan et al. ${ }^{13,27}$ This concept has also been applied by Dupont and $\mathrm{Liu},{ }^{28}$ who further employed partial crosslinking of individual compartments to stabilize the assemblies. ${ }^{12}$ A conceptually different approach is the formation of 
interpolyelectrolyte complexes (IPECs) ${ }^{29}$ as a tool to generate discontinuous micellar architectures, as has been shown for spherical ${ }^{17}$ and cylindrical ${ }^{30}$ examples with a compartmentalized IPEC shell. In some cases, the resulting charged particles could be further used for the building-up of concentric layers via the addition of oppositely charged polyelectrolytes. ${ }^{18,31,32}$

In this contribution, we demonstrate control over size, shape, and charge of $\mathrm{ABC}$ triblock terpolymer micelles via three different preparation pathways. The materials, polybutadieneblock-poly(tert-butyl methacrylate)-block-poly(2-(dimethylamino)ethyl methacrylate) (PB- $b$-P $t$ BMA- $b$-PDMAEMA, BTD) terpolymers, were synthesized via sequential living anionic polymerization. Further, depending on polymer-analogous modifications like ester hydrolysis (P $t$ BMA to poly(methacrylic acid), PMAA) or quaternization (PDMAEMA to PDMAEMAq), terpolymers with one or two either weak or strong polyelectrolytes are obtained. In that way, self-assembly in aqueous media leads to structures that are able to respond to changes in $\mathrm{pH}$, temperature, or salinity. For characterization of all structures discussed, both cryogenic transmission electron microscopy (cryo-TEM) and dynamic light scattering (DLS) were used.

\section{Experimental part}

\section{Synthesis}

Materials. sec-Butyllithium (Acros, $1.3 \mathrm{M}$ in cyclohexane/ hexane: 92/8) was used without further purification. Butadiene (Rießner-Gase) was passed through columns filled with molecular sieves ( $4 \AA$ ) and basic aluminium oxide. Afterwards, it was condensed into a glass reactor and stored over dibutylmagnesium. tert-Butyl methacrylate (BASF) and 2-(dimethylamino) ethyl methacrylate (Aldrich, 98\%) were first degassed by three freeze-thaw cycles on a high vacuum line. Then, tri- $n$-octylaluminium (Aldrich, $25 \mathrm{wt} \%$ in hexane) was added until a slight yellow color of the resulting mixture persisted. The solutions were stirred for $1 \mathrm{~h}$ and the calculated amount of monomer was condensed into previously weighed glass ampoules and stored in liquid nitrogen until use. THF (Fluka, p.a.) was distilled from $\mathrm{CaH}_{2}$ and $\mathrm{Na} / \mathrm{K}$ alloy. 1,1-Diphenylethylene (Acros, 98\%) was distilled from sec-butyllithium under reduced pressure. The solvents for the preparation of the micellar solutions were purchased in p.a. grade and used as delivered. Dimethyl sulfate (Aldrich, 99\%) and hydrochloric acid (Grüssing, 32\%) were used as received. All aqueous solutions were prepared either from Millipore water or buffer solutions in the range of $\mathrm{pH} 2$ to $\mathrm{pH} 10$ (VWR, AVS Titrinorm) with an ionic strength in the order of $0.05 \mathrm{M}$. Water was purified with a Milli-Q water purification system by Millipore.

Synthesis of BTD triblock terpolymers. Linear BTD triblock terpolymers were synthesized via sequential living anionic polymerization of the corresponding monomers in THF at low temperatures using sec-BuLi as initiator. Prior to the reaction, freshly distilled THF $(600 \mathrm{~mL})$ was treated with sec-BuLi at -20 ${ }^{\circ} \mathrm{C}$, followed by stirring overnight at room temperature to produce alkoxides to stabilize the living polybutadienyl chain ends during the polymerization. In a typical reaction, 1,3-butadiene (20.5 mL, $13.3 \mathrm{~g}, 0.246 \mathrm{~mol})$ was initiated with sec-BuLi $(0.2 \mathrm{~mL}, 0.3 \mathrm{mmol})$ at $-70{ }^{\circ} \mathrm{C}$ in $\mathrm{THF}$ and polymerized at $-10{ }^{\circ} \mathrm{C}$ for $8 \mathrm{~h}$. After polymerization of the first block, the living butadienyl chain ends were end-capped with 1,1-diphenylethylene $(0.11 \mathrm{~mL}, 0.11 \mathrm{~g}, 0.6 \mathrm{mmol})$ for $1 \mathrm{~h}$ at $-50{ }^{\circ} \mathrm{C}$ to attenuate the nucleophilicity. In this way, transfer reactions upon addition of the second monomer, $t$ BMA, could be suppressed $^{33,34}$ Subsequently, $t$ BMA $(9.3 \mathrm{~mL}, 8.2 \mathrm{~g}, 0.057 \mathrm{~mol})$ was added to the reaction mixture via syringe and stirred for $1 \mathrm{~h}$ at $-40{ }^{\circ} \mathrm{C}$. After polymerization of the second block, DMAEMA (20.2 $\mathrm{mL}, 18.9 \mathrm{~g}, 0.12 \mathrm{~mol}$ ) was added via syringe. During the polymerization of the PDMAEMA block, samples were taken at different reaction times and terminated with degassed isopropanol. The polymers were purified by dialysis against a water/ THF (2:3) mixture. Therefore, we could obtain two BTD triblock terpolymers with a constant ratio of first to second block but varying PDMAEMA content.

Preparation of micellar solutions from BTD terpolymers. The triblock terpolymer $\mathrm{B}_{800} \mathrm{~T}_{200} \mathrm{D}_{285}$ was dissolved in dioxane $(c=1$ $\mathrm{g} \mathrm{L}^{-1}$ ) and dialyzed against $\mathrm{pH} 8$ buffer solution. For all dialysis steps in this work, membranes of regenerated cellulose (Spectra/ Por, Roth) with a molecular weight cut-off (MWCO) of $3500 \mathrm{~g}$ $\mathrm{mol}^{-1}$ were used. After dialysis, a micellar stock solution in $\mathrm{pH} 8$ buffer with a concentration of $0.4 \mathrm{~g} \mathrm{~L}^{-1}$ was obtained. From this stock solution changes in $\mathrm{pH}$ were performed by dialyzing against the corresponding buffer solutions.

Hydrolysis of the PtBMA block. The BTD terpolymers were dissolved in dioxane at a concentration of $1 \mathrm{~g} \mathrm{~L}^{-1}$. A spatula of the stabilizer 2,6-di-tert-butyl-p-cresol (BHT) and a tenfold excess of hydrochloric acid relative to the ester moieties were added and the reaction mixture was refluxed at $120^{\circ} \mathrm{C}$ for $24 \mathrm{~h}$. Afterwards, the excess of $\mathrm{HCl}$ was removed by dialysis against deionized water. After dialysis, micellar stock solutions in deionized water with concentrations of approximately $0.5 \mathrm{~g} \mathrm{~L}^{-1}$ were obtained. From these stock solutions changes in $\mathrm{pH}$ or salinity were performed by dialyzing against the corresponding buffer solutions.

Quaternization of the PDMAEMA block. For quaternization the already hydrolyzed triblock terpolymer $\mathrm{B}_{800} \mathrm{MAA}_{200} \mathrm{D}_{285}$ was directly taken from the reaction mixture after hydrolysis and dialyzed against a dioxane/water mixture $(1: 1, \mathrm{v} / \mathrm{v})$. The dialysate was exchanged several times until the residual $\mathrm{HCl}$ was removed (checked via the $\mathrm{pH}$ ). Then the polymer solution in dioxane/water was treated with a fivefold excess of dimethyl sulfate (DMS) relative to the DMAEMA moieties. After stirring at room temperature for 5 days, the excess of quaternization agent was removed by dialysis against $\mathrm{pH} 10$ buffer solution. After dialysis, a micellar stock solution in $\mathrm{pH} 10$ buffer with a concentration of $0.5 \mathrm{~g} \mathrm{~L}^{-1}$ was obtained. From this stock solution changes in salinity were performed by dialyzing against the corresponding buffer solutions.

\section{Characterization}

Size exclusion chromatography (SEC). SEC measurements were performed at room temperature on a Waters instrument 
equipped with PSS SDV gel columns $(30 \times 8 \mathrm{~mm}, 5 \mu \mathrm{m}$ particle size) with $10^{2}, 10^{3}, 10^{4}$, and $10^{5} \AA$ pore sizes using RI and UV detection $(\lambda=254 \mathrm{~nm})$. THF with additional $0.25 \mathrm{wt} \%$ tetrabutylammonium bromide (TBAB) was used as eluent at a flow

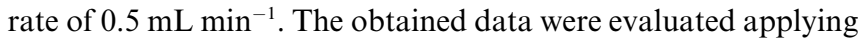
PS calibrations.

${ }^{1} \mathrm{H}$-Nuclear magnetic resonance (NMR) spectroscopy. ${ }^{1} \mathrm{H}-$ NMR spectra were recorded on a Bruker Ultrashield 300 spectrometer at an operating frequency of $300 \mathrm{MHz}$. $\mathrm{CDCl}_{3}$ was used as solvent and tetramethylsilane as internal standard.

MALDI-ToF mass spectrometry. MALDI-ToF MS analysis was performed on a Bruker Reflex III apparatus equipped with a $\mathrm{N}_{2}$ laser $(\lambda=337 \mathrm{~nm})$ in linear mode at an acceleration voltage of $20 \mathrm{kV}$. trans-2-[3-(4-tert-Butylphenyl)-2-methyl-2-propenylidene]malononitrile (DCTB, Fluka, 99.0\%) was used as a matrix material and silver trifluoroacetate (AgTFA, Sigma-Aldrich, $99.99 \%$ ) as an ionization agent. Samples were prepared from THF solution by mixing matrix, polymer, and salt in a ratio of $20: 5: 1(\mathrm{v} / \mathrm{v})$.

Fourier transform infrared (FTIR) spectroscopy. FTIR spectra were recorded on a Perkin Elmer Spectrum 100 FTIR spectrometer. The samples were introduced as freeze-dried powders.

Dynamic light scattering (DLS). DLS measurements were performed on an ALV DLS/SLS-SP 5022F compact goniometer system with an ALV 5000/E cross correlator and a He-Ne laser $(\lambda=632.8 \mathrm{~nm})$. The measurements were carried out in cylindrical scattering cells $(d=10 \mathrm{~mm})$ at an angle of $90^{\circ}$ and a temperature of $20{ }^{\circ} \mathrm{C}$. Prior to the light scattering measurements, the sample solutions were filtered using nylon filters (Magna, Roth) with a pore size of $5 \mu \mathrm{m}$. The CONTIN algorithm was applied to analyze the obtained correlation functions. Apparent hydrodynamic radii were calculated according to the Stokes-Einstein equation. Apparent polydispersities for the aggregates in solution were determined from unimodal peaks via the cumulant analysis.

Cryogenic transmission electron microscopy (cryo-TEM). For cryo-TEM studies, a drop $(\sim 2 \mu \mathrm{L})$ of the aqueous micellar solution ( $c \approx 0.5 \mathrm{~g} \mathrm{~L}^{-1}$ ) was placed on a lacey carbon-coated copper TEM grid (200 mesh, Science Services), where most of the liquid was removed with blotting paper, leaving a thin film stretched over the grid holes. The specimens were shock vitrified by rapid immersion into liquid ethane in a temperaturecontrolled freezing unit (Zeiss Cryobox, Zeiss NTS GmbH) and cooled to approximately $90 \mathrm{~K}$. The temperature was monitored and kept constant in the chamber during all of the preparation steps. After freezing the specimens, they were inserted into a cryo-transfer holder (CT3500, Gatan) and transferred to a Zeiss EM922 OMEGA EFTEM instrument. Examinations were carried out at temperatures around $90 \mathrm{~K}$. The microscope was operated at an acceleration voltage of $200 \mathrm{kV}$. Zero-loss filtered images $(\Delta E=0 \mathrm{eV})$ were taken under reduced dose conditions. All images were registered digitally by a bottommounted CCD camera system (Ultrascan 1000, Gatan), combined, and processed with a digital imaging processing system (Gatan Digital Micrograph 3.9 for GMS 1.4).
Estimation of the aggregation number, $\boldsymbol{N}_{\text {agg }}$. According to the core radius obtained via cryo-TEM, the aggregation number, $N_{\text {agg }}$, can be calculated with eqn (1):

$$
N_{\text {agg }}=\frac{m_{\text {core }}}{m_{\mathrm{PB}}^{\text {chain }}}=\frac{4 \pi N_{\mathrm{A}} \rho_{\mathrm{PB}} R_{\mathrm{core}}^{3}}{3 M_{\mathrm{PB}}^{\text {chain }}}
$$

where $m_{\text {core }}$ is the mass of the micellar core; $m_{\mathrm{PB}}^{\text {chain }}$ is the mass of an individual PB chain; $N_{\mathrm{A}}$ is the Avogadro constant; $\rho_{\mathrm{PB}}$ is the density of polybutadiene; $R_{\text {core }}$ is the radius of the micellar core according to cryo-TEM and $M_{\mathrm{PB}}^{\text {chain }}$ is the molecular weight of an individual PB chain. Please note that this method is just a rough estimation and strongly depends on the quality of the cryo-TEM micrographs for the determination of the core interface.

$\zeta$ Potential. The $\zeta$ potential was determined on a Malvern Zetasizer Nano ZS equipped with a He-Ne laser $(\lambda=632.8 \mathrm{~nm})$. The measurements were carried out in $1 \mathrm{~mL}$ disposable cuvettes with $\mathrm{Au}$ electrodes at a temperature of $25^{\circ} \mathrm{C}$. The measured electrophoretic mobilities $(u)$ were converted into $\zeta$ potentials via the Smoluchowski equation, $\zeta=u \eta / \varepsilon_{0} \varepsilon$ where $\eta$ denotes the viscosity and $\varepsilon_{0} \varepsilon$ the permittivity of the solution.

Turbidity measurements and titrations. Turbidity measurements were performed using a Metrohm Titrando 809 system equipped with a Spectrosense turbidity sensor (Metrohm, $\lambda=$ $523 \mathrm{~nm}$ ) and a Pt 1000 temperature sensor. The measurements were carried out in a thermostatted glass chamber. The temperature program $\left(0.25 \mathrm{~K} \mathrm{~min}^{-1}\right)$ was run by a LAUDA RE 306 thermostat. The turbidity measurements were performed with freshly prepared micellar solutions at a concentration of $0.5 \mathrm{~g}$ $\mathrm{L}^{-1}$. All measurements were conducted in buffer solutions to keep the $\mathrm{pH}$ constant over the entire temperature range. The solutions were degassed by applying vacuum (50-100 mbar) for $15 \mathrm{~min}$ at room temperature to minimize bubble formation during heating. For the turbidity titration, an additional dosing unit (Dosino 800, Metrohm) and an Aquatrode $\mathrm{pH}$ electrode were used. The titration was performed with $1.0 \mathrm{M} \mathrm{NaOH}$ solution at a temperature of $20^{\circ} \mathrm{C}$. Between the addition of each portion of $\mathrm{NaOH}$ an equilibration time of 5 min was employed.

\section{Results and discussion}

\section{Synthesis and molecular characterization of BTD block terpolymers}

Two polybutadiene-block-poly(tert-butyl methacrylate)-blockpoly(2-(dimethylamino)ethyl methacrylate) (PB- $b$-P $t$ BMA- $b$ PDMAEMA, BTD) triblock terpolymers were synthesized via sequential living anionic polymerization in THF at low temperatures in the presence of alkoxides. In this way, a high content of 1,2-polybutadiene ( $86 \%$, confirmed by ${ }^{1} \mathrm{H}-\mathrm{NMR}$ measurements) can be achieved. During the polymerization of the third block (PDMAEMA), samples were taken to obtain block terpolymers with varying PDMAEMA content. The main reason was to investigate the influence of the PDMAEMA block length on micellar structures and eventual responsive properties.

The molecular weights of the triblock terpolymers were determined by a combination of MALDI-ToF mass spectra (PB precursor) and ${ }^{1} \mathrm{H}-\mathrm{NMR}$ spectra. We obtained two BTD triblock 
Table 1 Molecular characteristics of the synthesized BTD triblock terpolymers and their precursors

\begin{tabular}{llcl}
\hline Sample $^{a}$ & Composition $^{b}$ & $M_{\mathrm{n}}{ }^{c} / \mathrm{kg} \mathrm{mol}^{-1}$ & PDI $^{d}$ \\
\hline $\mathrm{B}_{800}$ & $\mathrm{~B}_{100}$ & 42.9 & 1.03 \\
$\mathrm{~B}_{800} \mathrm{~T}_{200}$ & $\mathrm{~B}_{60} \mathrm{~T}_{40}$ & 71.7 & 1.05 \\
$\mathrm{~B}_{800} \mathrm{~T}_{200} \mathrm{D}_{85}$ & $\mathrm{~B}_{51} \mathrm{~T}_{33} \mathrm{D}_{16}$ & 85.1 & 1.05 \\
$\mathrm{~B}_{800} \mathrm{~T}_{200} \mathrm{D}_{285}$ & $\mathrm{~B}_{37} \mathrm{~T}_{24} \mathrm{D}_{39}$ & 116.5 & 1.10
\end{tabular}

${ }^{a}$ Subscripts denote the degrees of polymerization of the corresponding blocks. ${ }^{b}$ Subscripts denote the weight fractions of the corresponding blocks. ${ }^{c}$ Calculated from ${ }^{1} \mathrm{H}-\mathrm{NMR}$ spectra in $\mathrm{CDCl}_{3}$ using the absolute $M_{\mathrm{n}}$ of the first block from MALDI-ToF MS. ${ }^{d}$ Determined by SEC in THF with $0.25 \mathrm{wt} \%$ TBAB calibrated with PS standards.

terpolymers, $\mathrm{B}_{800} \mathrm{~T}_{200} \mathrm{D}_{85}$ and $\mathrm{B}_{800} \mathrm{~T}_{200} \mathrm{D}_{285}$ (subscripts denoting the degrees of polymerization of the corresponding blocks). Table 1 shows a summary of the molecular characteristics of the PB precursor $\left(\mathrm{B}_{800}\right)$, the $\mathrm{PB}-b$-P $t \mathrm{BMA}$ precursor $\left(\mathrm{B}_{800} \mathrm{~T}_{200}\right)$ and two BTD triblock terpolymers.

The SEC traces obtained in THF with $0.25 \mathrm{wt} \%$ tetrabutylammonium bromide (TBAB) as eluent are shown in Fig. 1. Both precursors and final block terpolymers exhibit narrow molecular weight distributions. A slight shoulder at approximately double molecular weight can be seen for the precursors, but we attribute this to chain coupling occurring during the sampling procedure, since it does not appear in the SEC trace of the final product.

\section{Micelle preparation pathways}

Starting from BTD triblock terpolymers, we studied three different systems for the self-assembly in aqueous solution, as shown in Scheme 1.

System I: the terpolymers were dissolved in a common solvent for all blocks (e.g. dioxane) and dialyzed against water at $\mathrm{pH} 8$. From this stock solution changes in $\mathrm{pH}$ were performed by dialyzing against the corresponding buffer solutions. This leads to micelles with a PB core, a PtBMA shell, and a double stimuli-

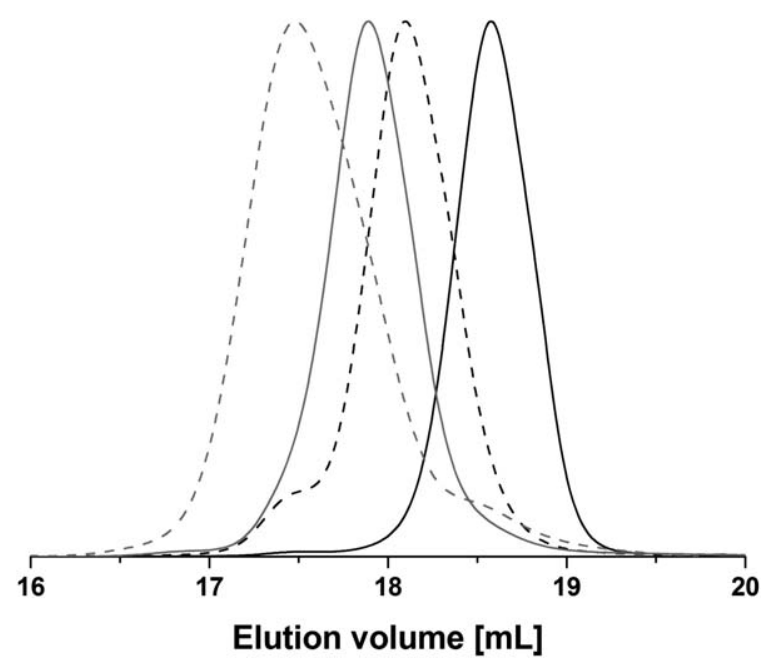

Fig. 1 SEC elution traces of $B_{800}$ (solid black line), $B_{800} T_{200}$ (dashed black line), $B_{800} T_{200} D_{85}$ (solid grey line), and $B_{800} T_{200} D_{285}$ (dashed grey line) using THF with $0.25 \mathrm{wt} \% \mathrm{TBAB}$ as eluent. responsive PDMAEMA corona. PDMAEMA is a weak polybase, which exhibits $\mathrm{pH}$ - and thermo-responsive properties. ${ }^{35}$

System II: the BTD triblock terpolymers are modified to generate two $\mathrm{pH}$-sensitive and hydrophilic compartments by hydrolysis of P $t$ BMA under acidic conditions to poly(methacrylic acid) (PMAA), a weak polyacid. ${ }^{17}$ In that way, polyampholytes containing both a polyacid and a polybase block are formed. The obtained PB- $b$-PMAA- $b$-PDMAEMA block terpolymers form different micellar structures depending on the solution conditions.

System III: here, we applied a two-step procedure in which the P $t$ BMA block is first hydrolyzed to PMAA, followed by quaternization of PDMAEMA, yielding a triblock terpolymer with a $\mathrm{pH}$-responsive middle block (PMAA), and a strong polycation as the end block (PDMAEMAq).

\section{System I: pH- and thermo-responsive micelles}

The block terpolymer $\mathrm{B}_{800} \mathrm{~T}_{200} \mathrm{D}_{285}$ is dialyzed from dioxane into aqueous solution at different $\mathrm{pH}$ values. As PDMAEMA is a weak polybase with $\mathrm{p} K_{\mathrm{b}, \mathrm{app}} \sim 7.8,{ }^{35}$ solutions of $\mathrm{pH} 4,8$, and 10 were chosen to demonstrate the $\mathrm{pH}$-responsive behavior of this system. First, we undertook dynamic light scattering (DLS) studies. The corresponding DLS CONTIN plots are shown in Fig. 2. Bimodal distributions are obtained at all three $\mathrm{pH}$ values, hinting towards cluster formation. Besides, micellar solutions of $\mathrm{B}_{800} \mathrm{~T}_{200} \mathrm{D}_{285}$ at $\mathrm{pH} \geq 8$ precipitated after several days. Therefore, micellar solutions were freshly prepared in all cases discussed here. Note that the DLS CONTIN plots in Fig. 2 depict intensity-weighted distributions, overestimating the amount of larger aggregates being present. We compare intensity- to numberweighted micellar distributions at $\mathrm{pH} 8$ in Fig. 3C.

As shown in Fig. 2, individual micelles from $B_{800} T_{200} D_{285}$ exhibit the largest hydrodynamic radius at $\mathrm{pH} 4\left(\left\langle R_{\mathrm{h}}\right\rangle_{z}=45 \mathrm{~nm}\right.$, clusters at $\left.\left\langle R_{\mathrm{h}}\right\rangle_{z}=168 \mathrm{~nm}\right)$. This can be explained by the $\mathrm{pH}$ responsive behavior of PDMAEMA, resulting in a highly stretched conformation of the corona chains at low $\mathrm{pH}$. With increasing $\mathrm{pH}$, the degree of ionization of the PDMAEMA chains decreases, leading to shrinkage of the micellar corona. Thus, the micelles at pH $8\left(\left\langle R_{\mathrm{h}}\right\rangle_{z}=35 \mathrm{~nm}\right.$, clusters at $\left\langle R_{\mathrm{h}}\right\rangle_{z}=92$ $\mathrm{nm})$ and $\mathrm{pH} 10\left(\left\langle R_{\mathrm{h}}\right\rangle_{z}=31 \mathrm{~nm}\right.$, clusters at $\left.\left\langle R_{\mathrm{h}}\right\rangle_{z}=81 \mathrm{~nm}\right)$ are significantly smaller as compared to $\mathrm{pH} 4$.

To further investigate the structure of the $B_{800} T_{200} D_{285}$ micelles, we performed cryogenic transmission electron microscopy (cryo-TEM) experiments at pH 8 (Fig. 3A). Uniform spherical micelles with a grey $\mathrm{PB}$ core and several dark spots on the core surface are visible. This is even more pronounced in the enlargement of a single micelle in the inset in Fig. 3A. We assume that these dark patches on the $\mathrm{PB}$ core originate from the hydrophobic P $t$ BMA block. Apparently, the formation of spherical compartments of $\mathrm{P} t \mathrm{BMA}$ is favored compared to a continuous shell around the PB core. We have shown earlier that polybutadiene-block-poly(2-vinylpyridine)-block-poly(tertbutyl methacrylate) (BVT) terpolymers form similar structures in acetone, a non-solvent for polybutadiene. ${ }^{11}$ In that case, compartmentalization has been attributed to the high incompatibility between the first (PB) and the second (P2VP) block $\left(\chi_{\mathrm{BV}}=0.325\right) .{ }^{36}$ At least according to literature values, the incompatibility between $\mathrm{PB}$ and $\mathrm{P} t \mathrm{BMA}$ here is supposed to be 


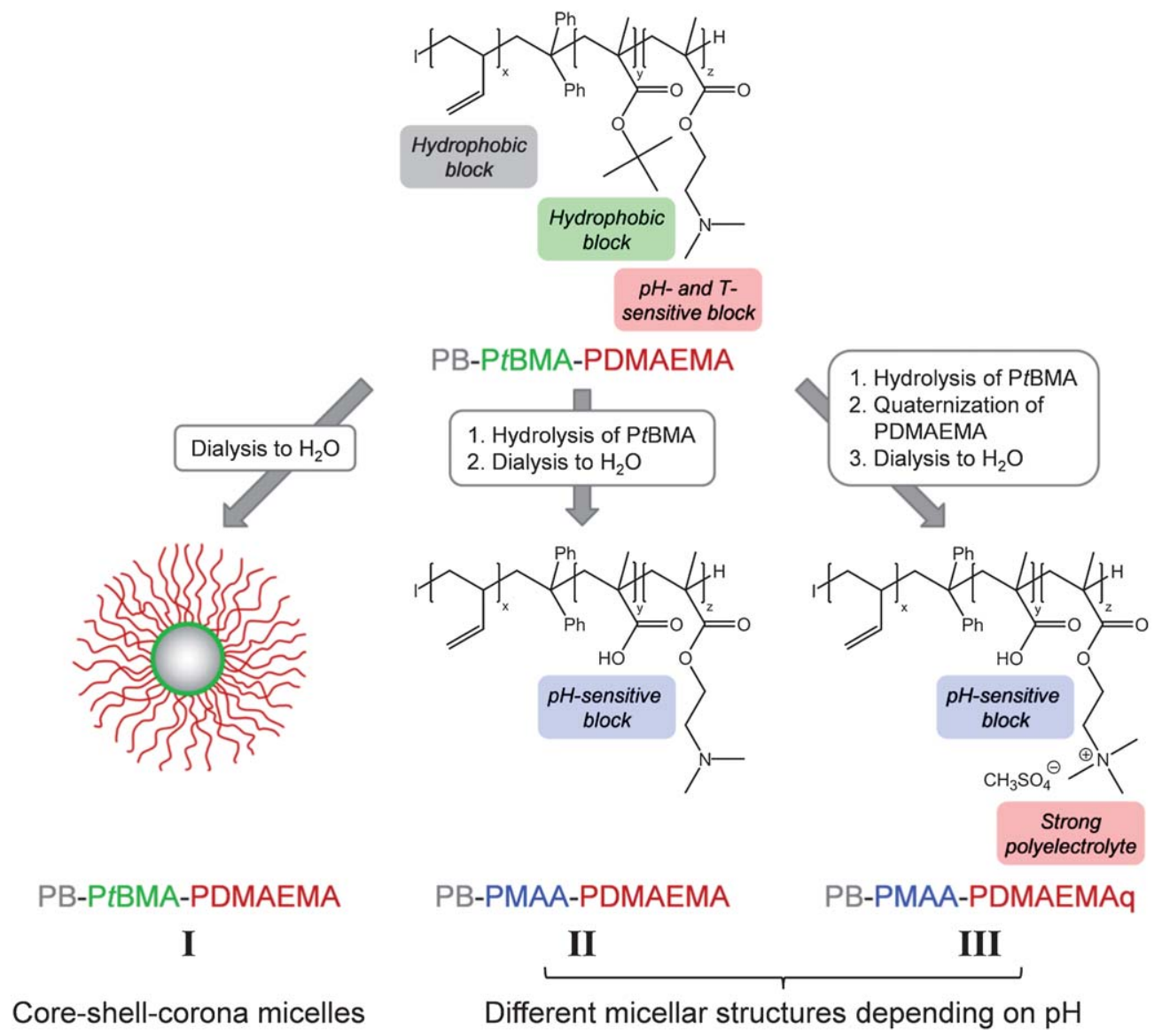

Scheme 1 Three different systems of micellar aggregates prepared from BTD triblock terpolymers in aqueous solution.

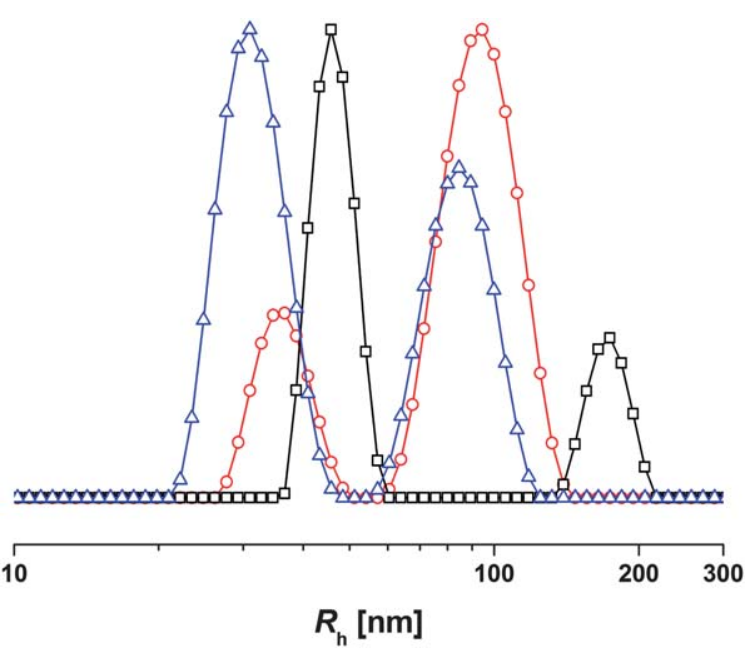

Fig. 2 Intensity-weighted DLS CONTIN plots for $\mathrm{B}_{800} \mathrm{~T}_{200} \mathrm{D}_{285}$ micelles in aqueous solution $\left(c=0.4 \mathrm{~g} \mathrm{~L}^{-1}\right)$ at different $\mathrm{pH}$ values; $\mathrm{pH} 4(-\square-$, black, $\left\langle R_{\mathrm{h}}\right\rangle_{z}=45 \mathrm{~nm}$ and $168 \mathrm{~nm}$ (clusters)), $\mathrm{pH} 8\left(-\mathrm{O}_{-}\right.$, red, $\left\langle R_{\mathrm{h}}\right\rangle_{z}=$ $35 \mathrm{~nm}$ and $92 \mathrm{~nm}$ (clusters)), and $\mathrm{pH} 10\left(-\triangle-\right.$, blue, $\left\langle R_{\mathrm{h}}\right\rangle_{z}=31 \mathrm{~nm}$ and $81 \mathrm{~nm}$ (clusters)).

less pronounced $\left(\chi_{\mathrm{BT}}=0.007\right) .{ }^{36}$ The PDMAEMA corona, surrounding the patchy core, is not visible in the cryo-TEM micrographs due to its low electron density. The proposed solution structure of these multicompartment-core micelles is presented in Fig. 3B together with the corresponding block lengths.

In addition, the cryo-TEM micrographs were analyzed quantitatively to estimate the micellar size and the radius of the PB core. The averaged values obtained from approximately 50 micelles for each sample are listed together with the corresponding standard deviations in Table 2 (see further below). For $\mathrm{B}_{800} \mathrm{~T}_{200} \mathrm{D}_{285}$, an average radius of the micellar core, including the PtBMA patches, of $16 \mathrm{~nm}$ was obtained.

If estimated with eqn (1), this corresponds to $N_{\mathrm{agg}} \approx 230$ for $\mathrm{B}_{800} \mathrm{~T}_{200} \mathrm{D}_{285}$ at $\mathrm{pH}$ 8. According to cryo-TEM, we could not observe any agglomerates, as indicated by DLS experiments (Fig. 2 and 3C), although both measurements were performed at the same concentrations. One has to keep in mind that a numberweighted distribution (TEM) is compared to a $z$-average (DLS) for a moderately polydisperse sample.

Since the corona-forming block of the $\mathrm{B}_{800} \mathrm{~T}_{200} \mathrm{D}_{285}$ micelles, PDMAEMA, is a $\mathrm{pH}$ - and thermo-responsive polymer, ${ }^{35,37}$ the solubility of the micelles can be tuned by two external stimuli. At low $\mathrm{pH}\left(\mathrm{p} K_{\mathrm{b}, \mathrm{app}} \approx 7.8\right)$, the corona chains become protonated and positively charged, leading to additional stabilization in solution. Therefore, changes in $\mathrm{pH}$ directly influence the LCST of the PDMAEMA corona. Cloud points were determined via turbidity measurements applying a temperature ramp with constant heating rate $\left(0.25 \mathrm{~K} \mathrm{~min}^{-1}\right)$ for micellar solutions at 

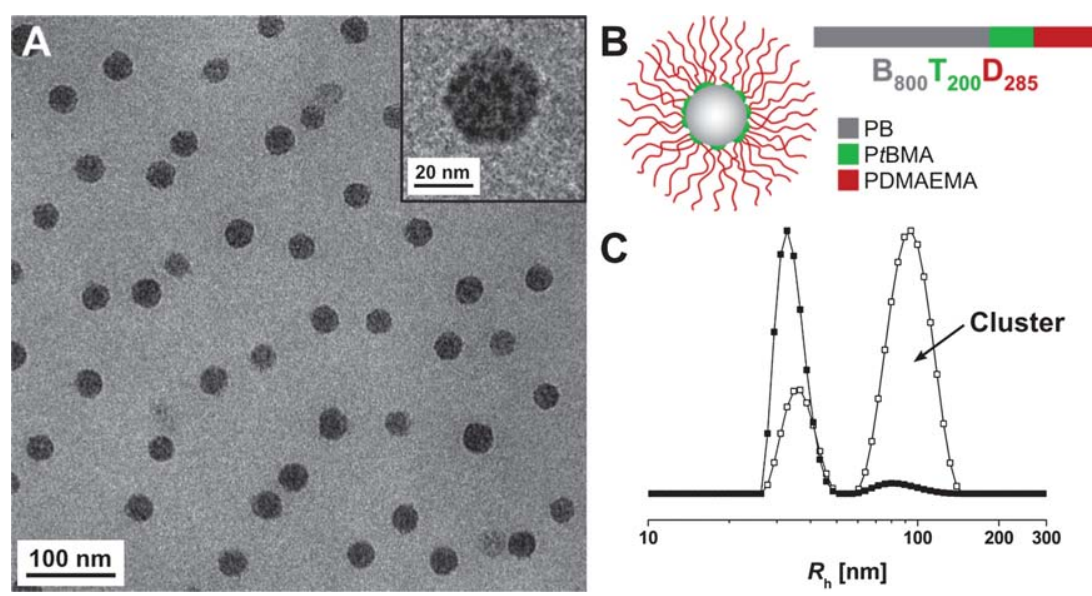

Fig. 3 Cryo-TEM micrograph of $\mathrm{B}_{800} \mathrm{~T}_{200} \mathrm{D}_{285}$ in aqueous solution $(c=0.4 \mathrm{~g} \mathrm{~L}-1)$ at $\mathrm{pH} 8$ (A), the inset shows an enlargement of a single micelle; block terpolymer composition and proposed solution structure at $\mathrm{pH} 8(\mathrm{~B})$; DLS CONTIN plots for $\mathrm{B}_{800} \mathrm{~T}_{200} \mathrm{D}_{285}$ micelles in aqueous solution $\left(c=0.4 \mathrm{~g} \mathrm{~L} \mathrm{~L}^{-1}\right)$ at pH 8 (C); intensity-weighted $\left(-\square-,\left\langle R_{\mathrm{h}}\right\rangle_{z}=35 \mathrm{~nm}\right.$ and $\left.92 \mathrm{~nm}\right)$ and number-weighted CONTIN plot $\left(-\boldsymbol{-}-,\left\langle R_{\mathrm{h}}\right\rangle_{z}=33 \mathrm{~nm}\right.$ and $\left.83 \mathrm{~nm}\right)$.

Table 2 Hydrodynamic radii, average compartment sizes with standard deviations, and $\zeta$ potentials of $\mathrm{B}_{800} \mathrm{~T}_{200} \mathrm{D}_{285}$ and $\mathrm{B}_{800} \mathrm{MAA}_{200} \mathrm{D}_{x}$ micelles at different $\mathrm{pH}$ values

\begin{tabular}{llllll}
\hline & & System II & & \\
\cline { 3 - 6 } & $\begin{array}{l}\text { System I } \\
\mathrm{B}_{800} \mathrm{~T}_{200} \mathrm{D}_{285} \mathrm{pH} 8\end{array}$ & $\mathrm{~B}_{800} \mathrm{MAA}_{200} \mathrm{D}_{285} \mathrm{pH} \mathrm{2}$ & $\mathrm{B}_{800} \mathrm{MAA}_{200} \mathrm{D}_{285} \mathrm{pH} 5$ & $\mathrm{~B}_{800} \mathrm{MAA}_{200} \mathrm{D}_{285} \mathrm{pH}_{10}$ & $\mathrm{~B}_{800} \mathrm{MAA}_{200} \mathrm{D}_{85} \mathrm{pH}_{5}$ \\
\hline$\left\langle R_{\mathrm{h}}\right\rangle_{z}{ }^{a} / \mathrm{nm}$ & 35 & 157 & 141 & 99 & 75 \\
$\left\langle R_{\mathrm{TEM}}\right\rangle_{n} / \mathrm{nm}$ & - & - & $149 \pm 11$ & $118 \pm 9$ & - \\
$R_{\text {core }} / \mathrm{nm}$ & $16 \pm 1$ & $34 \pm 1$ & $37 \pm 1$ & $34 \pm 4$ & $38 \pm 2$ \\
$D_{\text {corona }} / \mathrm{nm}$ & - & - & $111 \pm 11$ & $84 \pm 10$ & - \\
$\zeta / \mathrm{mV}$ & - & +35 & +41 & -11 & +42
\end{tabular}

${ }^{a}$ Determined by DLS. ${ }^{b}$ Determined by image analysis of cryo-TEM micrographs.

different $\mathrm{pH}$ values. Plamper et al. observed a considerable drop of the $\mathrm{pH}$ with increasing temperature in pure water. ${ }^{35}$ To avoid this, we performed the measurements in buffer solutions (ionic strength $\approx 0.05 \mathrm{M}$ ) to ensure constant $\mathrm{pH}$.

A typical turbidity measurement at $\mathrm{pH} 8$ is shown in Fig. 4A. Close to the cloud point $\left(T_{\mathrm{cl}}=50{ }^{\circ} \mathrm{C}\right)$, the transmittance decreases abruptly and the micelles precipitate. The cloud points were obtained as the intersection of the tangents at the onset of turbidity. The values measured at different $\mathrm{pH}$ values are shown in Fig. 4B. A significant shift of the cloud points to higher temperatures with decreasing $\mathrm{pH}$ can be seen. At $\mathrm{pH} \geq 9$, the PDMAEMA chains are almost uncharged (degree of neutralization $<2 \%$ at $\mathrm{pH} 9) .{ }^{38}$ With decreasing $\mathrm{pH}$, the PDMAEMA chains become charged, resulting in a shift of the cloud points to higher temperatures. At $\mathrm{pH} 7$, where most PDMAEMA units are protonated, the LCST reaches a temperature of $79^{\circ} \mathrm{C}$.
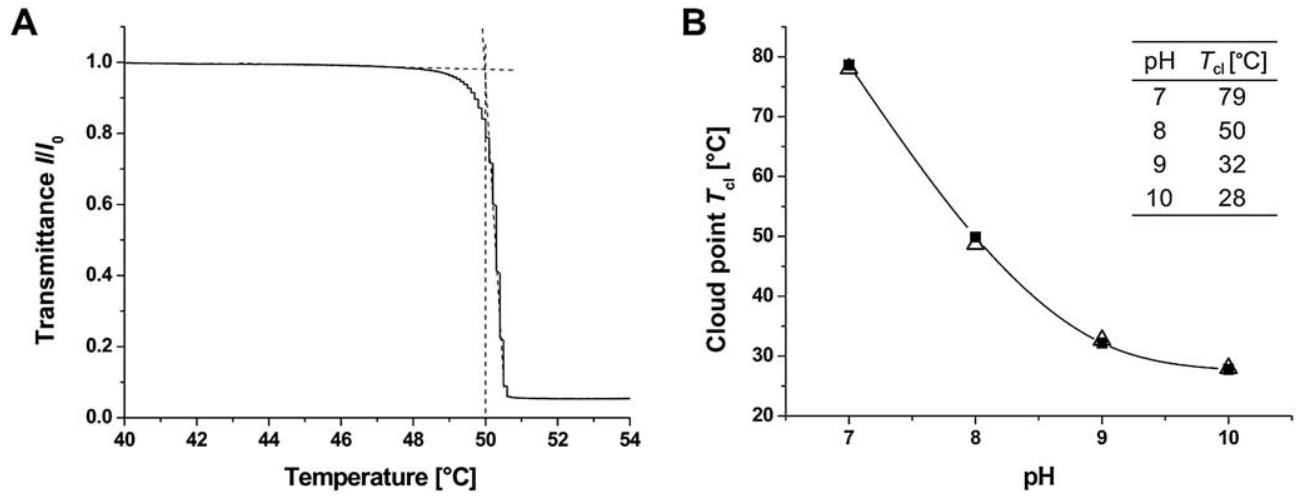

Fig. 4 Determination of cloud points via turbidity measurements, here: $\mathrm{B}_{800} \mathrm{~T}_{200} \mathrm{D}_{285}$ in $\mathrm{pH} 8$ buffer solution $\left(c=0.5 \mathrm{~g} \mathrm{~L}^{-1}\right)(\mathrm{A})$; cloud points $T_{\mathrm{cl}}$ of $\mathrm{B}_{800} \mathrm{~T}_{200} \mathrm{D}_{285}$ at different $\mathrm{pH}$ values as determined via turbidimetry (-口-) compared with literature values for $\left(\mathrm{PDMAEMA}_{240}\right)_{11}$ stars $^{35}(-\triangle-)(\mathrm{B})$, the inset lists the obtained cloud points $T_{\mathrm{cl}}$. 
A direct comparison of the obtained cloud points with literature values for linear and star-shaped PDMAEMA, however, is difficult, since the LCST of PDMAEMA also depends on the molecular weight. ${ }^{35}$ For linear PDMAEMA with a degree of polymerization $\left(\mathrm{DP}_{n}=133\right)$ corresponding to approximately half the length of the PDMAEMA block $\left(\mathrm{DP}_{n}=285\right)$ in the terpolymer used here, considerably higher cloud points have been reported for $\mathrm{pH} \geq 8\left(\right.$ e.g. $T_{\mathrm{cl}}=43^{\circ} \mathrm{C}$ for $\left.\mathrm{pH} 9\right)$. Our values are comparable to those reported for star-shaped $\left(\text { PDMAEMA }_{240}\right)_{11}$ with an arm number of 11 and 240 monomer units per arm, which is comparable to our material (Fig. 4B). This indicates that the corona chains here rather behave like arms of polyelectrolyte stars instead of linear polymers.

\section{System II: micelles with tunable charge and architecture}

Hydrolysis of the PtBMA block to PMAA under acidic conditions generates a second $\mathrm{pH}$-responsive hydrophilic block with an opposite charge. ${ }^{17}$ FTIR and ${ }^{1} \mathrm{H}-\mathrm{NMR}$ spectroscopy indicate a complete hydrolysis of the PtBMA compartment (Fig. S1-S3, ESI $\dagger$ ).

Upon this, the material is turned into a polyampholyte, as both a weak polyacid, PMAA ( $\left.K_{\text {a,app }} \approx 5.5\right)$, ${ }^{39}$ and a weak polybase, PDMAEMA $\left(\mathrm{p} K_{\mathrm{b}, \mathrm{ppp}} \approx 7.8\right),{ }^{35}$ are present. Two ampholytic terpolymers, $\mathrm{B}_{800} \mathrm{MAA}_{200} \mathrm{D}_{285}$ and $\mathrm{B}_{800} \mathrm{MAA}_{200} \mathrm{D}_{85}$ (subscripts denoting the degrees of polymerization of the corresponding blocks), were studied. After the modification, stock solutions of the micelles were prepared in deionized water at $\sim \mathrm{pH}$ 5. From these stock solutions changes in $\mathrm{pH}$ or salinity were performed by dialysis.

$\mathrm{B}_{800} \mathrm{MAA}_{200} \mathrm{D}_{285}$ micelles were titrated from $\mathrm{pH} 2$ to $\mathrm{pH} 12$ with $\mathrm{NaOH}(1.0 \mathrm{M})$ and the transmittance of the solution was recorded. Fig. 5A depicts the obtained titration curve. The turbidity starts to increase at approximately $\mathrm{pH}$ 5.5. Due to both polyelectrolyte blocks being present, the micelles are supposed to form intra-micellar interpolyelectrolyte complexes ( $\mathrm{im}$-IPECs) of deprotonated PMAA and protonated PDMAEMA in a $\mathrm{pH}$ range from 5.5 to 8 . So-formed insoluble $\mathrm{im}$-IPEC domains should lead to a significant decrease in the solubility of the micelles and, hence, to agglomeration. At $\mathrm{pH}$ 6.6, the maximum turbidity is reached and the micelles precipitate. Under these conditions, complete charge neutrality might be assumed. We therefore denote this point as the micellar isoelectric point $(\mathrm{m}$ IEP). At $\mathrm{pH}>6.6$, the degree of ionization of the PMAA block exceeds that of the PDMAEMA block. Strikingly, this allows for a re-dissolution of the micelles with a negative net charge due to deprotonated PMAA. At $\mathrm{pH}>9$, a homogeneous micellar solution is obtained.

Fig. 5B shows an enlargement of the titration curve of $\mathrm{B}_{800} \mathrm{MAA}_{200} \mathrm{D}_{285}$. Between $\mathrm{pH} 4$ and $\mathrm{pH} 9$, two regions with slightly different slopes can be distinguished. Presumably, these regions correspond to the buffer regimes of the weak polyelectrolytes PMAA and PDMAEMA, respectively. Taking into account the point of half neutralization of either the polyacid or the polybase, $\mathrm{p} K_{\mathrm{a} \text {,app }} \approx 5.5$ for PMAA and $\mathrm{p} K_{\mathrm{b} \text {,app }} \approx 7.8$ for PDMAEMA can be determined. This corresponds well to the values reported in the literature. ${ }^{35,39}$

As shown in Fig. 5A, $\mathrm{B}_{800} \mathrm{MAA}_{200} \mathrm{D}_{285}$ micelles are not colloidally stable within the $\mathrm{pH}$ range from 5.5 to 8 . To screen the charges present and to prevent $\mathrm{im}$-IPEC formation, additional salt $(0.5 \mathrm{M} \mathrm{NaCl})$ was introduced into the system via dialysis directly after hydrolysis. The increase in ionic strength prevented flocculation of the micelles even around the $m$-IEP. DLS measurements in the presence of $0.5 \mathrm{M} \mathrm{NaCl}$ are shown exemplarily for $\mathrm{pH} 6$ in Fig. $6\left(\left\langle R_{\mathrm{h}}\right\rangle_{z}=112 \mathrm{~nm}\right)$.

DLS CONTIN plots of $\mathrm{B}_{800} \mathrm{MAA}_{200} \mathrm{D}_{285}$ micelles at $\mathrm{pH} 2,5$, and 10 (in the absence of additional salt) are shown in Fig. 6. At $\mathrm{pH} 2$, a hydrodynamic radius of $\left\langle R_{\mathrm{h}}\right\rangle_{z}=157 \mathrm{~nm}$ is obtained, presumably due to a completely stretched PDMAEMA corona. As PMAA is hydrophobic at $\mathrm{pH} 2$, it is expected to collapse onto the PB core. At $\mathrm{pH} 5$, the micelles shrink $\left(\left\langle R_{\mathrm{h}}\right\rangle_{z}=141 \mathrm{~nm}\right)$. Under these conditions, PDMAEMA is still thoroughly protonated, but also a small amount of ionized PMAA groups should be present. Hence, some loose im-IPECs might be formed leading to the observed decrease in micellar size. At $\mathrm{pH} 10$, the micelles are considerably smaller $\left(\left\langle R_{\mathrm{h}}\right\rangle_{z}=99 \mathrm{~nm}\right)$. Here, PDMAEMA is uncharged and the middle block, PMAA, is completely ionized. We expect structural transitions between the shell and the corona to occur at this $\mathrm{pH}$.

We further subjected these micellar solutions to cryo-TEM: Fig. 7A provides an overview at $\mathrm{pH} \mathrm{2}$, and an enlargement is provided in the inset. Both micrographs show a spherical, grey $\mathrm{PB}$ core with an approximate radius of $34 \mathrm{~nm}$. All sizes measured
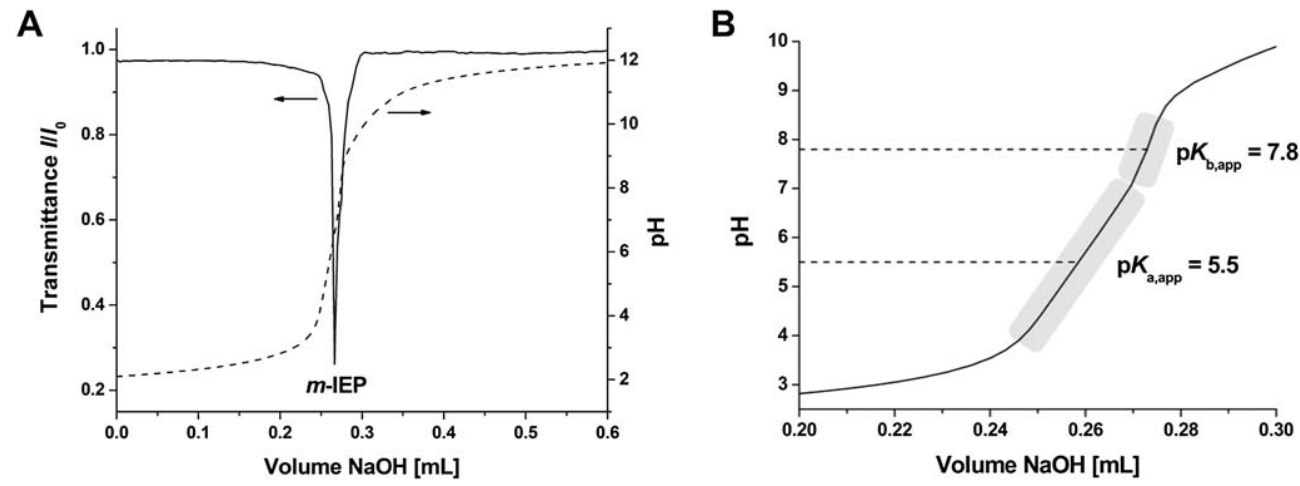

Fig. 5 Turbidity titration of $\mathrm{B}_{800} \mathrm{MAA}_{200} \mathrm{D}_{285}$ in aqueous solution $\left(c=0.5 \mathrm{~g} \mathrm{~L}^{-1}\right)$ with $1.0 \mathrm{M} \mathrm{NaOH}$, micellar isoelectric point $(m$-IEP) highlighted at $\mathrm{pH}$ 6.6 (A); enlarged region of the titration curve in (A) showing the two buffer regimes of PMAA and PDMAEMA with $\mathrm{p} K_{\mathrm{a}, \mathrm{app}}$ and $\mathrm{p} K_{\mathrm{b}, \text { app }}$ values (B). 


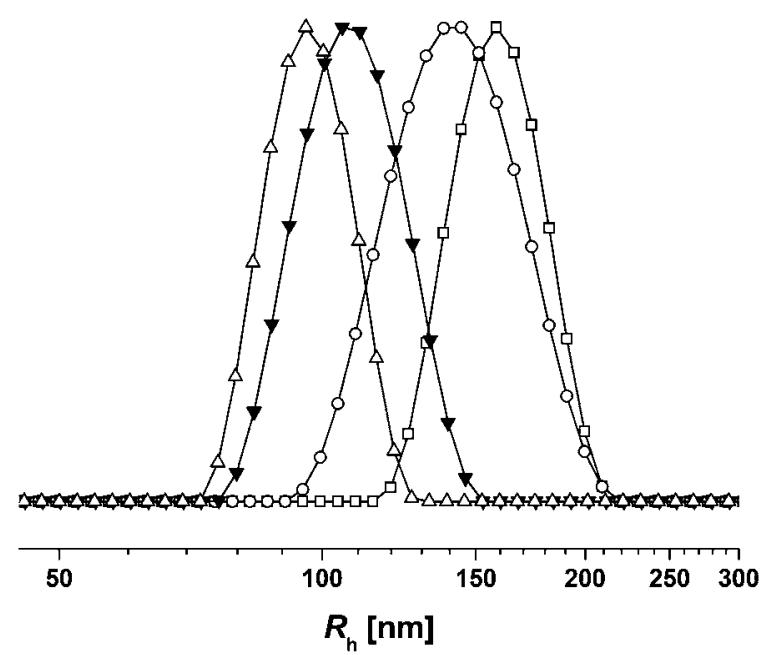

Fig. 6 Intensity-weighted DLS CONTIN plots for $\mathrm{B}_{800} \mathrm{MAA}_{200} \mathrm{D}_{285}$ micelles in aqueous solution $\left(c=0.5 \mathrm{~g} \mathrm{~L}^{-1}\right)$ at different $\mathrm{pH}$ and salinity; $\mathrm{pH} 2\left(-\square-,\left\langle R_{\mathrm{h}}\right\rangle_{z}=157 \mathrm{~nm}, \mathrm{PDI}=1.09\right), \mathrm{pH} 5\left(-\mathrm{O}_{-},\left\langle R_{\mathrm{h}}\right\rangle_{z}=141 \mathrm{~nm}\right.$, PDI $=1.12)$, pH $10\left(-\triangle-,\left\langle R_{\mathrm{h}}\right\rangle_{z}=99 \mathrm{~nm}, \mathrm{PDI}=1.07\right)$, and $\mathrm{pH} 6$ with additional $0.5 \mathrm{M} \mathrm{NaCl}\left(-\boldsymbol{\nabla}-,\left\langle R_{\mathrm{h}}\right\rangle_{z}=112 \mathrm{~nm}, \mathrm{PDI}=1.08\right)$.

at different $\mathrm{pH}$ values from cryo-TEM data are also summarized in Table 2. The PB core is surrounded by a PDMAEMA corona, but the shell of collapsed PMAA cannot be clearly distinguished. The vitrified film for this sample was rather thick and, as a result, micelles in different layers of the film can be found and seem to overlap in the 2-D projection. We thus refrained from measuring any core-to-core distances here.

Cryo-TEM of $\mathrm{B}_{800} \mathrm{MAA}_{200} \mathrm{D}_{285}$ micelles at $\mathrm{pH} 5$ is shown in Fig. 7B. The appearance of the micellar aggregates clearly has changed: instead of a core-shell-corona structure, we observed several dark spots on the grey $\mathrm{PB}$ core. At this stage it is difficult to say whether these originate from loose im-IPEC domains formed between negatively charged PMAA and protonated PDMAEMA or from collapsed, uncharged PMAA. Eventual hydrogen bonding might also occur between uncharged species, further promoting this phenomenon. Only few such patches are visible, as the majority of PMAA units are uncharged under these conditions. The PB core, including the im-IPEC and PMAA domains, exhibits an approximate radius of $37 \mathrm{~nm}$. The remaining PDMAEMA corona is hardly visible, even in the enlarged view. With $149 \mathrm{~nm}$, the average radius of the micelles as measured from the core-to-core distance fits quite well to the hydrodynamic radius of $141 \mathrm{~nm}$ obtained by DLS. Fig. 7E shows the proposed solution structure. To simplify matters, the fraction of uncharged PMAA is depicted as a thin continuous shell around the PB core, which might, however, not reflect the real situation in solution.

The situation is entirely different at $\mathrm{pH} 10$ (Fig. 7C): PDMAEMA is uncharged and PMAA is completely ionized under these conditions. Further, the micelles seem to have undergone a structural transition. Especially in the enlarged view dark patches are present on the PB core. These originate from the uncharged, collapsed PDMAEMA. We expect the ionized
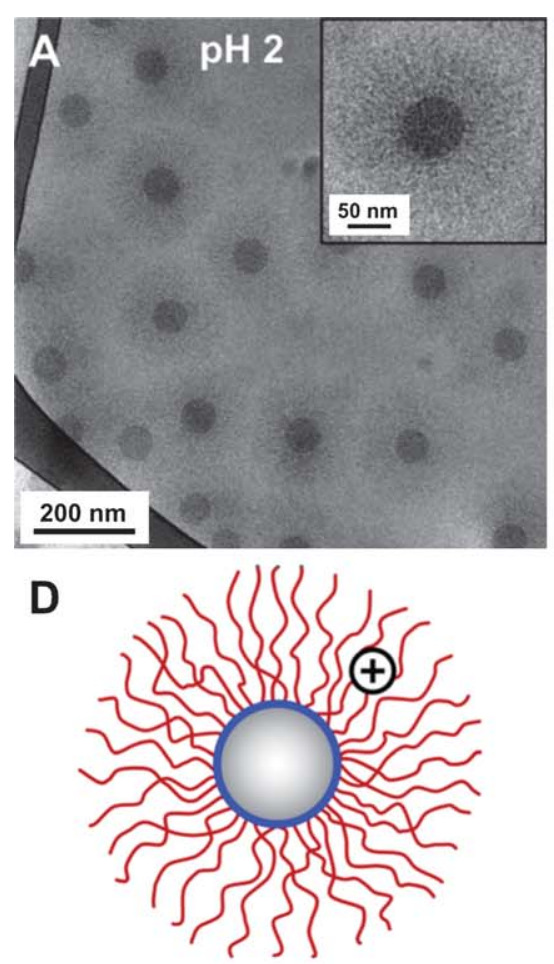

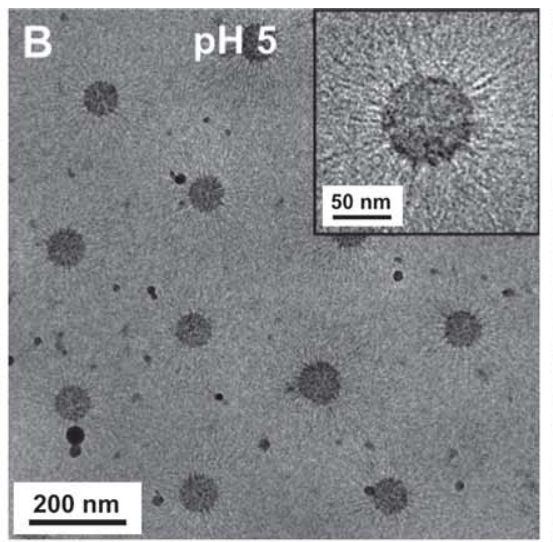

E

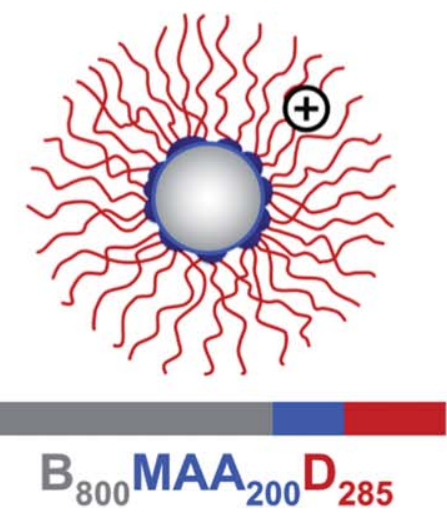

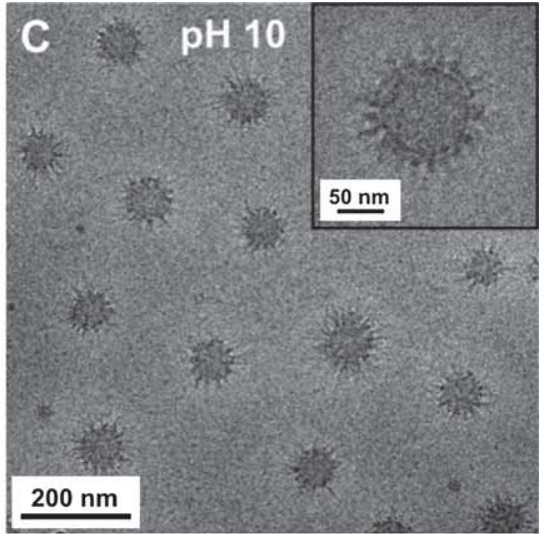

$\mathbf{F}$

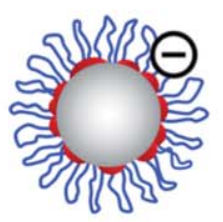

PB

PMAA

IPEC PMAA/PDMAEMA excess PDMAEMA

Fig. 7 Cryo-TEM micrographs of $\mathrm{B}_{800} \mathrm{MAA}_{200} \mathrm{D}_{285}$ in aqueous solution $\left(c=0.5 \mathrm{~g} \mathrm{~L}^{-1}\right)$ at different $\mathrm{pH}$ values; $\mathrm{pH} 2$ (A), $\mathrm{pH} 5$ (B), and pH 10 (C), the insets in each part show an enlargement of a single micelle; proposed solution structure at pH 2 (D), pH 5 (E), and pH 10 (F). 

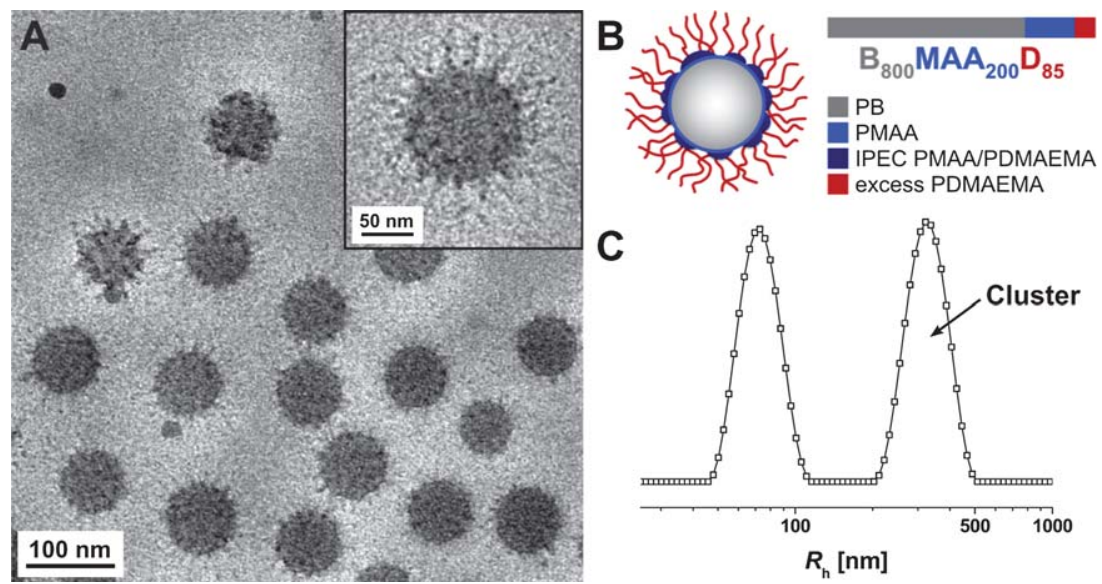

Fig. 8 Cryo-TEM micrographs of $\mathrm{B}_{800} \mathrm{MAA}_{200} \mathrm{D}_{85}$ in aqueous solution $\left(c=0.5 \mathrm{~g} \mathrm{~L}^{-1}\right)$ at pH $5(\mathrm{~A})$, the inset shows an enlargement of a single micelle; block terpolymer composition and proposed solution structure at pH 5 (B); intensity-weighted DLS CONTIN plot for $\mathrm{B}_{800} \mathrm{MAA}_{200} \mathrm{D}_{85}$ micelles $(c=0.5$ $\left.\mathrm{g} \mathrm{L}^{-1}\right)$ at $\mathrm{pH} 5\left(\mathrm{C},\left\langle R_{\mathrm{h}}\right\rangle_{z}=75 \mathrm{~nm}\right.$ and $\left.320 \mathrm{~nm}\right)$.

PMAA to form loops, resulting in flower-like micelles, as depicted in Fig. 7F. The average radius of the micellar core at $\mathrm{pH}$ $10\left(R_{\text {core }}=34 \mathrm{~nm}\right)$ is quite similar to the values at $\mathrm{pH} 2\left(R_{\text {core }}=\right.$ $34 \mathrm{~nm})$ and pH $5\left(R_{\text {core }}=37 \mathrm{~nm}\right)$. An estimation with eqn (1) yields aggregation numbers $N_{\text {agg }}$ in the range of 2000-3000 terpolymer chains. Since we assume that the corona of the flower-like micelles is formed by PMAA chains, the micelles are expected to exhibit a negative net charge. This could be proven by $\zeta$ potential measurements $(\zeta=-11 \mathrm{mV})$. At low $\mathrm{pH}, \zeta$ potentials of $+35 \mathrm{mV}(\mathrm{pH} 2)$ and $+41 \mathrm{mV}(\mathrm{pH} \mathrm{5})$ were obtained (Table 2). The positive net charge of the micelles at low $\mathrm{pH}$ originates from a highly protonated PDMAEMA corona.

To study the influence of the corona-forming block length on the micellar structure and stability, micelles were prepared using the same protocol for the second terpolymer, $\mathrm{B}_{800} \mathrm{MAA}_{200} \mathrm{D}_{85}$, where the PDMAEMA block is shorter than the PMAA. Both the size and the architecture were characterized as shown before by DLS and cryo-TEM. The DLS CONTIN plot in Fig. 8C exhibits a bimodal distribution at $\mathrm{pH} 5\left(\left\langle R_{\mathrm{h}}\right\rangle_{z}=75 \mathrm{~nm}\right.$ and 320 $\mathrm{nm})$. Apparently, there is a high tendency for cluster formation. If compared to $\mathrm{B}_{800} \mathrm{MAA}_{200} \mathrm{D}_{285}\left(\left\langle R_{\mathrm{h}}\right\rangle_{z}=157 \mathrm{~nm}\right)$, the micelles of $\mathrm{B}_{800} \mathrm{MAA}_{200} \mathrm{D}_{85}$ are distinctly smaller, most probably due to the reduced length of the corona-forming PDMAEMA block.

Cryo-TEM of $\mathrm{B}_{800} \mathrm{MAA}_{200} \mathrm{D}_{85}$ micelles at $\mathrm{pH} 5$ (Fig. 8A) discloses a similar structure as seen for $\mathrm{B}_{800} \mathrm{MAA}_{200} \mathrm{D}_{285}$ under these conditions. The micelles exhibit several dark spots present on the grey PB core, originating from loose $i m$-IPECs. Since only a small fraction of the PMAA units is ionized at $\mathrm{pH} 5$ and, thus, participates in im-IPEC formation, the micelles still exhibit a short PDMAEMA corona which, however, could not be visualized in cryo-TEM. The PB core, including the $\mathrm{im}$-IPEC and PMAA domains, exhibits an average radius of $38 \mathrm{~nm}$ (Table 2). This reveals only a slight increase both in core radius if compared to $\mathrm{B}_{800} \mathrm{MAA}_{200} \mathrm{D}_{285}\left(R_{\text {core }}=37 \mathrm{~nm}\right)$. The proposed solution structure of these crew-cut type aggregates is depicted in Fig. 8B. Again, the uncharged PMAA units are depicted as a thin continuous shell around the PB core for simplicity reasons.

$\zeta$ Potential measurements in water at $\mathrm{pH} 5$ yielded a value of $+42 \mathrm{mV}$. The positive net charge of the micelles confirms the assumption of a short corona of non-complexed PDMAEMA.
Typically, colloidal particles exhibiting $\zeta$ potential values higher than $+30 \mathrm{mV}$ or lower than $-30 \mathrm{mV}$ are considered to be colloidally stable and withstand agglomeration. ${ }^{40}$ This suggests that there is efficient repellence between the positively charged micelles of $\mathrm{B}_{800} \mathrm{MAA}_{200} \mathrm{D}_{85}$ and is in accordance with cryoTEM, where no larger aggregates were found. DLS measurements, which were conducted at the same concentration, revealed the occurrence of clusters, which we again ascribe to the $z$ average obtained via this method.

\section{System III: core-shell-corona micelles with a pH-responsive shell}

$\mathrm{B}_{800} \mathrm{~T}_{200} \mathrm{D}_{285}$ was modified using a two-step procedure similar to the earlier work carried out on BVT systems. ${ }^{17}$ After hydrolysis of the P $t$ BMA block to PMAA, PDMAEMA was quaternized with dimethyl sulfate. ${ }^{18}$ FTIR spectroscopy confirms the methylation of the amino functions of PDMAEMA (Fig. S4A and B,

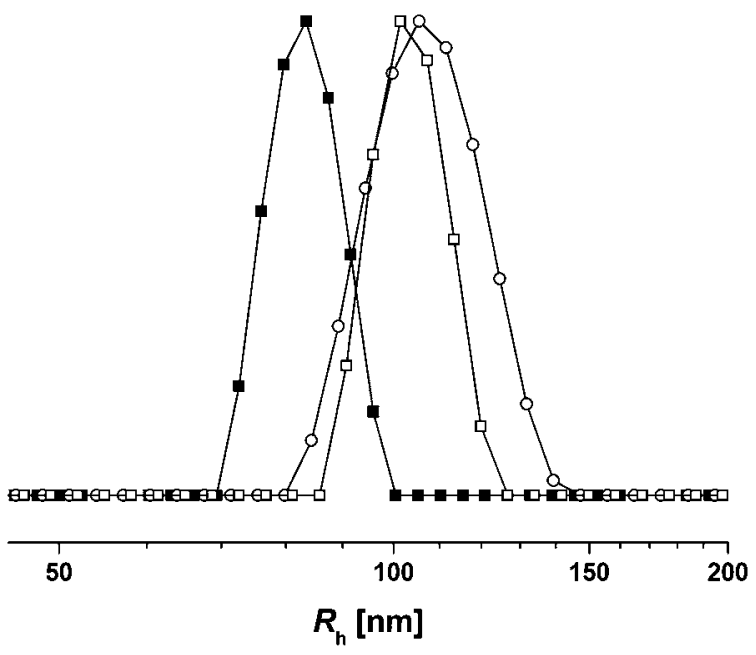

Fig. 9 DLS CONTIN plots for $\mathrm{B}_{800} \mathrm{MAA}_{200} \mathrm{Dq}_{285}$ micelles in aqueous solution $\left(c=0.5 \mathrm{~g} \mathrm{~L}^{-1}\right)$ at different $\mathrm{pH}$ values; $\mathrm{pH} 10\left(-\square-,\left\langle R_{\mathrm{h}}\right\rangle_{z}=104\right.$ $\mathrm{nm}, \mathrm{PDI}=1.06), \mathrm{pH} 4\left(-\mathrm{O}_{-},\left\langle R_{\mathrm{h}}\right\rangle_{z}=107 \mathrm{~nm}, \mathrm{PDI}=1.08\right)$, and $\mathrm{pH} 10$ with $1.0 \mathrm{M} \mathrm{NaCl}\left(-\mathbf{-}-,\left\langle R_{\mathrm{h}}\right\rangle_{z}=84 \mathrm{~nm}\right.$, PDI $\left.=1.06\right)$. 
ESI $\dagger$ ). PDMAEMAq behaves as a strong polyelectrolyte, rendering ampholytic triblock terpolymers, $\mathrm{B}_{800} \mathrm{MAA}_{200} \mathrm{Dq}_{285}$, with a $\mathrm{pH}$-responsive middle block, PMAA, and a permanently charged cationic end block, PDMAEMAq. Core-shell-corona micelles with a soft $\mathrm{PB}$ core, a shell with a $\mathrm{pH}$-dependent composition, and a positively charged PDMAEMAq corona are expected to form in aqueous solution. At high $\mathrm{pH}$, im-IPECs can be formed between negatively charged PMAA and positively charged PDMAEMAq. According to the degrees of polymerization, the micelles should still exhibit a positive net charge due to an excess of PDMAEMAq. Since the formation of IPECs can be suppressed by salt, we prepared different samples: starting from a stock solution of $\mathrm{B}_{800} \mathrm{MAA}_{200} \mathrm{Dq}_{285}$ in $\mathrm{pH} 10$ buffer solution, the micelles were transferred to $\mathrm{pH} 4$ and $\mathrm{pH} 10$ with additional $1.0 \mathrm{M} \mathrm{NaCl}$. The corresponding DLS CONTIN plots are shown in Fig. 9.

At $\mathrm{pH}$ 10, the micelles exhibit a hydrodynamic radius of 104 $\mathrm{nm}$. This is significantly smaller than the size obtained earlier (System II) at $\mathrm{pH}$ 2. Here, the major fraction of the corona chains is complexed due to im-IPEC formation with ionized PMAA, reducing the length of the PDMAEMAq corona. For $\mathrm{pH} 4$, the size of the micelles increases slightly and the distribution seems to broaden. As PMAA is uncharged at $\mathrm{pH} \mathrm{4}$, the im-IPEC shell seems to re-dissolve and a thin shell of collapsed PMAA is expected to form around the PB core. Surprisingly, this takes place even at such low salinity (the used buffer solutions introduce $\sim 0.05 \mathrm{M}$ salt). We tentatively explain this by the rather loose IPEC formation between PMAA and PDMAEMAq. Thus, the length of the PDMAEMAq corona increases, yielding a radius of $\left\langle R_{\mathrm{h}}\right\rangle_{z}=107 \mathrm{~nm}$. In addition, the micelles were dialyzed against $\mathrm{pH} 10$ buffer solution with additional $1.0 \mathrm{M} \mathrm{NaCl}$, resulting in a contraction to $\left\langle R_{\mathrm{h}}\right\rangle_{z}=84 \mathrm{~nm}$. The increase in salinity leads to a screening of charges and the complete dissolution of any im-IPEC domains formed. In all cases, a spherical shape of the micelles is indicated by angle-dependent DLS measurements through the extrapolation of the decay rate $\Gamma_{q \rightarrow 0}=0$, shown exemplarily for $\mathrm{B}_{800} \mathrm{MAA}_{200} \mathrm{Dq}_{285}$ at $\mathrm{pH} 10$

Table 3 Hydrodynamic radii and average compartment sizes with standard deviations of $\mathrm{B}_{800} \mathrm{MAA}_{200} \mathrm{Dq}_{285}$ micelles at different $\mathrm{pH}$ values

\begin{tabular}{llll}
\hline & $\mathrm{pH} 4$ & $\mathrm{pH} 10$ & $\mathrm{pH} 10 ; 1.0 \mathrm{M} \mathrm{NaCl}$ \\
\hline$\left\langle R_{\mathrm{h}}\right\rangle_{z}{ }^{a} / \mathrm{nm}$ & 107 & 104 & 84 \\
$\left\langle R_{\mathrm{TEM}}\right\rangle_{n}{ }^{b} / \mathrm{nm}$ & $113 \pm 7$ & $115 \pm 9$ & - \\
$R_{\text {core }} / \mathrm{nm}$ & $32 \pm 5$ & $36 \pm 4$ & $28 \pm 4$ \\
$D_{\text {shell }} / \mathrm{nm}$ & $11 \pm 1$ & $31 \pm 2$ & $5 \pm 1$ \\
$D_{\text {corona }}{ }^{b} / \mathrm{nm}$ & $71 \pm 5$ & $48 \pm 10$ & -
\end{tabular}

${ }^{a}$ Determined by DLS. ${ }^{b}$ Determined by image analysis of cryo-TEM micrographs.
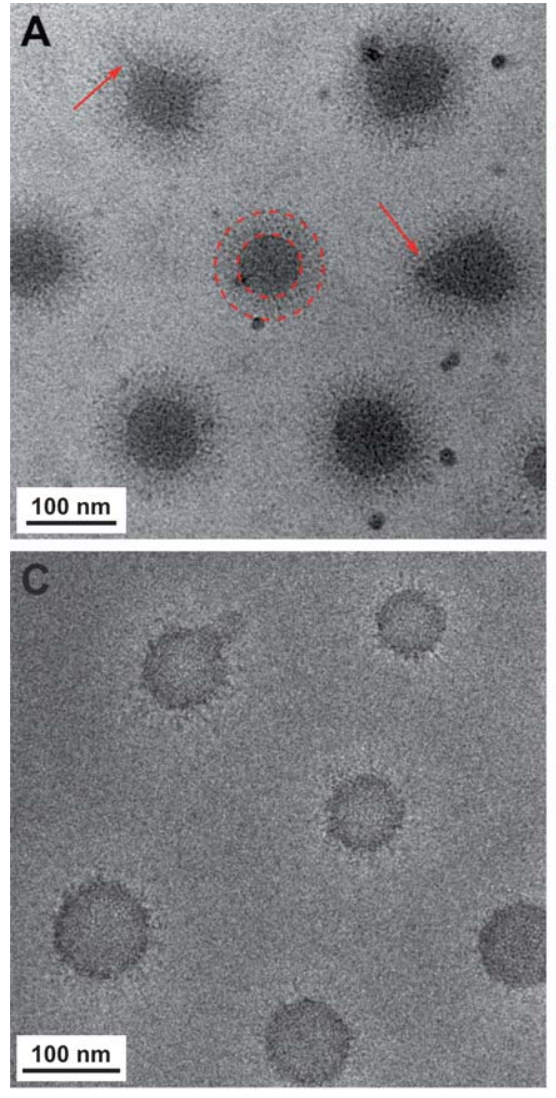
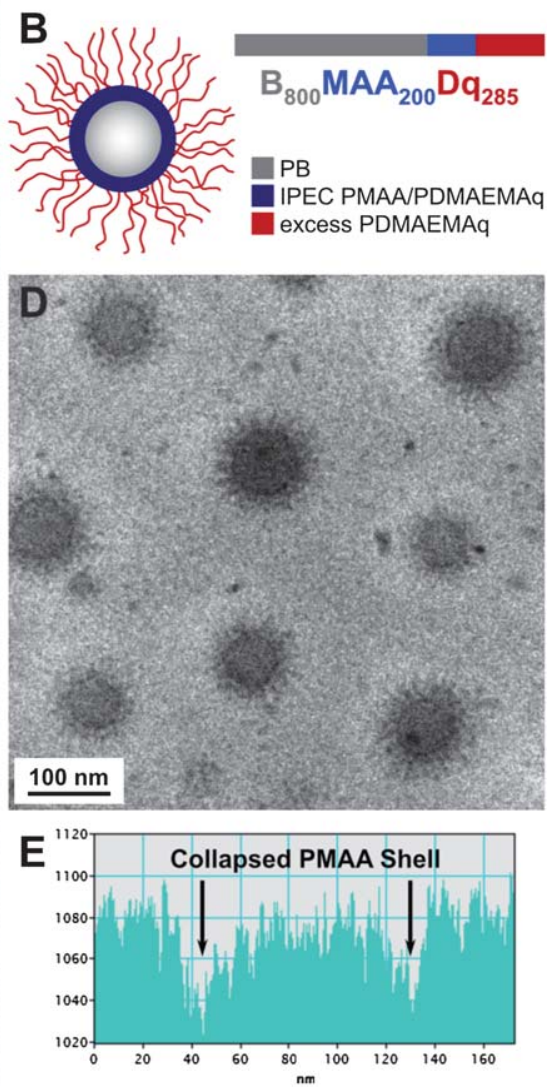

Fig. 10 Cryo-TEM micrographs of $\mathrm{B}_{800} \mathrm{MAA}_{200} \mathrm{Dq}_{285}$ in aqueous solution $\left(c=0.5 \mathrm{~g} \mathrm{~L}^{-1}\right)$ at different $\mathrm{pH}$ values; $\mathrm{pH} 10$ ((A), arrows highlight protrusions from the core, dashed circles indicate dimensions of the core and the im-IPEC shell), $\mathrm{pH} 4$ (C), and $\mathrm{pH} 10$ with $1.0 \mathrm{M} \mathrm{NaCl}$ (D); block terpolymer composition and proposed solution structure at $\mathrm{pH} 10$ (B); grey-scale analysis of a single micelle in (C) demonstrating the formation of a collapsed PMAA shell (E). 
(Fig. S5A, and hydrodynamic radii of the micelles extrapolated to infinite dilution, Fig. S5B, ESI $\dagger$ ).

To further elucidate the structure of the $\mathrm{B}_{800} \mathrm{MAA}_{200} \mathrm{Dq}_{285}$ micelles, cryo-TEM was performed. The corresponding micrographs are shown in Fig. 10. Fig. 10A depicts the situation at $\mathrm{pH}$ 10 , confirming the existence of core-shell-corona micelles with an im-IPEC shell. The micelles exhibit a thick, grey shell around the dark PB core, probably due to im-IPEC formation between PMAA and PDMAEMAq. The average dimensions of the individual compartments (core, shell, and corona) were determined from cryo-TEM micrographs for 50 micelles at different $\mathrm{pH}$ values. The values and the corresponding standard deviations are listed in Table 3. The micellar core exhibits an average radius of $36 \mathrm{~nm}$ at $\mathrm{pH} 10$ and the shell has a thickness of $31 \mathrm{~nm}$. Further, the size of the micelles was compared to the core-to-core distance in cryo-TEM $(115 \mathrm{~nm})$, which is in good agreement with the results from DLS measurements. Fig. 10B shows the proposed micellar structure at high $\mathrm{pH}$.

As can also be seen in Fig. 10A, the PB core is not perfectly spherical, rather deformed and protrusions from the core into the im-IPEC shell (indicated by arrows in Fig. 10A) are found. Similar structures have recently been observed for multicompartment micelles of $\mathrm{ABC}$ (linear and miktoarm star) terpolymers in water. ${ }^{18,41}$ In all cases reported, hydrophobic bridges between PB micellar cores seemed to occur due to the low glass transition temperature of the core-forming block. These findings suggest that the interfacial tension between the PB core and the im-IPEC shell is rather low, as the core does not adopt an ideal spherical shape.

Besides the observed protrusions, Fig. 10A also shows that the electron density of the im-IPEC shell is lower as compared to the PB core. This again suggests rather weak IPEC formation between PMAA and PDMAEMAq, leading to a relatively thick and loose im-IPEC shell. In contrast, earlier studies on triblock terpolymer micelles with $i m$-IPECs formed between poly (1-methyl-2-vinylpyridinium) (P2VPq) and poly(sodium methacrylate) (PMANa) blocks showed collapsed and very dense im-IPEC domains. ${ }^{17}$

Fig. 10C shows $\mathrm{B}_{800} \mathrm{MAA}_{200} \mathrm{Dq}_{285}$ micelles after dialysis to $\mathrm{pH}$ 4. Instead of a thick, loose im-IPEC shell, a thin, dark shell can be observed. We assume that this thin shell represents collapsed PMAA, indicating the dissolution of the former im-IPEC shell. This is also shown in the grey-scale analysis of one micellar aggregate in Fig. 10E. In general, IPECs are dissolved by the addition of salt and should be stable against changes in $\mathrm{pH}$. However, taking into account the rather loose IPEC formed in this particular case, the IPEC stability might be lower. Similar observations have been made for the $\mathrm{pH}$-dependent complexation between double hydrophilic acrylamide-based block copolymers and oppositely charged polyelectrolytes. ${ }^{42}$ Also here, changes in $\mathrm{pH}$ were sufficient to reversibly form/disassemble such IPECs. The core radius at $\mathrm{pH} 4$ with $32 \mathrm{~nm}$ is slightly smaller if compared to $\mathrm{pH} 10\left(R_{\text {core }}=36 \mathrm{~nm}\right)$.

The cryo-TEM micrograph at $\mathrm{pH} 10$ with additional $1.0 \mathrm{M}$ $\mathrm{NaCl}$ (Fig. 10D) may also serve as an indication for the dynamic nature of these micelles. Clearly, the structure has changed, as now a thin, dark shell around the PB core is visible. This demonstrates the dissolution of the im-IPEC taking place, rendering a shell of swollen PMAA. The size of the PB core decreased to $28 \mathrm{~nm}$, which, taking into account the error of the core-size determination via cryo-TEM $(\sim 10 \%)$, is another hint towards dynamic properties of the structures, caused by the soft PB core. However, estimated values for $N_{\text {agg }}(\sim 2500(\mathrm{pH} 10)$, $1200(\mathrm{pH} 10+1.0 \mathrm{M} \mathrm{NaCl})$, eqn (1)) do not allow for a conclusive statement at this point. As unimer exchange for non-ionic PB- $b$-PEO systems in water has not been observed at all, ${ }^{43}$ at least on experimental time-scales, we tentatively ascribe the dynamics observed here to micellar fusion/fission processes. Also here, hydrophobic bridges between individual micelles may play a role. ${ }^{18,41}$ Apart from the pure dimension, also the shape of the micelles has changed, as now only spherical aggregates are present. This might indicate that the interfacial tension between the PB core and the PMAA shell is higher as compared to the imIPEC without additional salt.

\section{Conclusion}

We have introduced a versatile and multi-responsive $\mathrm{ABC}$ block terpolymer, PB- $b$-P $t$ BMA- $b$-PDMAEMA. Depending on the preparation pathway, different micellar structures showing a diverse responsiveness to a variety of external stimuli and with differing solution characteristics can be formed.

We described situations where aggregates with one or two polyelectrolyte blocks are involved. Besides the rather obvious response to changes in $\mathrm{pH}$ or salinity, the use of PDMAEMA as the third compartment introduces additional temperature sensitivity. We showed that such micelles exhibit certain dynamic characteristics, which are mainly attributed to the soft coreforming block, PB. Even more, rearrangements in shell and corona lead to an observed transition from star-like to flowerlike micelles.

Several aspects which emerged during this work are interesting for future studies: the rather loose IPEC formation between PMAA and PDMAEMAq, the fact that these im-IPECs can be released even by changes in $\mathrm{pH}$ and the possibility to crosslink the PB core of the micelles in future work. The latter would prevent any changes in size or shape of the particles. Furthermore, these complex nanostructures are interesting systems for the selective loading of the individual micellar compartments with drugs or nanoparticles of different polarity of functionality.

\section{Acknowledgements}

The authors thank Susanne Edinger for the MALDI-ToF measurements and Christina Löffler for the SEC measurements. E.B. gratefully acknowledges financial support from the Free State of Bavaria for a scholarship within the BayEFG.

\section{References}

1 R. Weberskirch and H. Ringsdorf, Meeting of the HCM Network: Functional, Photoreactive and Polymerizable Amphiphilic Systems in Organized Media, Patras, Greece, 27 September, 1995.

2 H. Ringsdorf, P. Lehmann and R. Weberskirch, Book of Abstracts, 217th ACS National Meeting, Anaheim, CA, 21-25 March, 1999.

3 J. Du and R. K. O'Reilly, Chem. Soc. Rev., 2011, 40, 2402-2416.

4 A. Laschewsky, Curr. Opin. Colloid Interface Sci., 2003, 8, 274-281.

5 J.-F. Lutz and A. Laschewsky, Macromol. Chem. Phys., 2005, 206, 813-817.

6 T. P. Lodge, A. Rasdal, Z. B. Li and M. A. Hillmyer, J. Am. Chem. Soc., 2005, 127, 17608-17609. 
7 A. Laschewsky, J.-N. Marsat, K. Skrabania, H. von Berlepsch and C. Böttcher, Macromol. Chem. Phys., 2010, 211, 215-221.

8 J.-N. Marsat, M. Heydenreich, E. Kleinpeter, H. von Berlepsch, C. Böttcher and A. Laschewsky, Macromolecules, 2011, 44, 20922105.

9 C.-A. Fustin, V. Abetz and J.-F. Gohy, Eur. Phys. J. E: Soft Matter Biol. Phys., 2005, 16, 291-302.

10 K. Skrabania, H. von Berlepsch, C. Böttcher and A. Laschewsky, Macromolecules, 2010, 43, 271-281.

11 F. Schacher, A. Walther, M. Ruppel, M. Drechsler and A. H. E. Müller, Macromolecules, 2009, 42, 3540-3548.

12 R. H. Zheng, G. J. Liu and X. H. Yan, J. Am. Chem. Soc., 2005, 127, $15358-15359$.

13 H. G. Cui, Z. Y. Chen, S. Zhong, K. L. Wooley and D. J. Pochan, Science, 2007, 317, 647-650.

14 Z. B. Li, E. Kesselman, Y. Talmon, M. A. Hillmyer and T. P. Lodge, Science, 2004, 306, 98-101.

15 Z. B. Li, M. A. Hillmyer and T. P. Lodge, Langmuir, 2006, 22, 94099417.

16 M. Uchman, M. Štěpánek, K. Procházka, G. Mountrichas, S. Pispas, I. K. Voets and A. Walther, Macromolecules, 2009, 42, 5605-5613.

17 F. Schacher, A. Walther and A. H. E. Müller, Langmuir, 2009, 25, 10962-10969.

18 C. V. Synatschke, F. H. Schacher, M. Förtsch, M. Drechsler and A. H. E. Müller, Soft Matter, 2011, 7, 1714-1725.

19 H. Schmalz, J. Schmelz, M. Drechsler, J. Yuan, A. Walther, K. Schweimer and A. M. Mihut, Macromolecules, 2008, 41, 3235-3242.

20 B. Fang, A. Walther, A. Wolf, Y. Y. Xu, J. Y. Yuan and A. H. E. Müller, Angew. Chem., Int. Ed., 2009, 48, 2877-2880.

21 J. Z. Du and S. P. Armes, Soft Matter, 2010, 6, 4851-4857.

22 S. Kubowicz, J.-F. Baussard, J.-F. Lutz, A. F. Thünemann, H. von Berlepsch and A. Laschewsky, Angew. Chem., Int. Ed., 2005, 44, 5262-5265.

23 Z. B. Li, M. A. Hillmyer and T. P. Lodge, Nano Lett., 2006, 6, 12451249.

24 N. Saito, C. Liu, T. P. Lodge and M. A. Hillmyer, Macromolecules, $2008, \mathbf{4 1}, 8815-8822$.
25 C. Liu, M. A. Hillmyer and T. P. Lodge, Langmuir, 2009, 25, 13718 13725.

26 N. Saito, C. Liu, T. P. Lodge and M. A. Hillmyer, ACS Nano, 2010, 4, 1907-1912.

27 R. C. Hayward and D. J. Pochan, Macromolecules, 2010, 43, 35773584.

28 J. Dupont and G. Liu, Soft Matter, 2010, 6, 3654-3661.

29 V. A. Kabanov, Russ. Chem. Rev., 2005, 74, 3-20.

30 F. H. Schacher, T. Rudolph, M. Drechsler and A. H. E. Müller, Nanoscale, 2011, 3, 288-297.

31 F. Schacher, E. Betthausen, A. Walther, H. Schmalz, D. V. Pergushov and A. H. E. Müller, ACS Nano, 2009, 3, 2095-2102.

32 D. V. Pergushov, O. V. Borisov, A. B. Zezin and A. H. E. Müller, $A d v$. Polym. Sci., 2011, 131, 241, DOI: 10.1007/12_2010_102.

33 D. Freyss, P. Rempp and H. Benoît, J. Polym. Sci., Part B: Polym. Lett., 1964, 2, 217-222.

34 R. P. Quirk, T. Yoo, Y. Lee, J. Kim and B. Lee, Adv. Polym. Sci., 2000, 153, 67-106.

35 F. A. Plamper, M. Ruppel, A. Schmalz, O. Borisov, M. Ballauff and A. H. E. Müller, Macromolecules, 2007, 40, 8361-8366.

36 F. Schacher, J. Yuan, H. G. Schoberth and A. H. E. Müller, Polymer, 2010, 51, 2021-2032.

37 F. A. Plamper, A. Schmalz, E. Penott-Chang, M. Drechsler, A. Jusufi, M. Ballauff and A. H. E. Müller, Macromolecules, 2007, 40, 56895697.

38 F. A. Plamper, A. Schmalz, M. Ballauff and A. H. E. Müller, J. Am. Chem. Soc., 2007, 129, 14538-14539.

39 H. Dautzenberg, W. Jaeger, J. Kötz, B. Philipp, C. Seidel and D. Stscherbina, Polyelectrolytes, Carl Hanser Verlag, München, 1994.

40 T. M. Riddick, Control of Colloid Stability Through Zeta Potential, Livingston Press, Wynnewood, 1968.

41 A. Walther and A. H. E. Müller, Chem. Commun., 2009, 1127-1129.

42 M. G. Kellum, A. E. Smith, S. K. York and C. L. McCormick, Macromolecules, 2010, 43, 7033-7040.

43 Y.-Y. Won, H. T. Davis and F. S. Bates, Macromolecules, 2003, 36, 953-955. 